\title{
Performance Measurement of Telephone Network and Service
}

\section{Sigit Haryadi}

Institut Teknologi Bandung

February 2018

\section{Paper DOI 10.17605/OSF.IO/5C7QA}

Citation: Haryadi, S. (2018, February 27). Performance Measurement of Telephone Network and Service. Retrieved from osf.io/preprints/inarxiv/5c7qa

\section{Abstract}

This paper summarizes my papers and books, which reports on studies concerning the performance measurement of telephone networks and services, particularly on mobile networks. In detail, the telephone network and service quality measurements are grouped into two, the first is a measurement that aims to measure the provider's customer satisfaction, performed by the provider for internal purposes, or to report to the regulator, and the second measurement goal is that the provider and/or by the vendor in relation to the quality assurance provided by the vendor to the provider. In detail, the first type of measurement uses a sampling technique to refer to the subjective method, otherwise, the second type performs aggregate measurements to refer to the Signaling Ladder Diagram of the telephone services.

\section{Types of QoE and QoS Measurement of Phone Network and Service}

Measurement of telephone service quality is grouped into two, the first is a measurement that aims to measure provider's customer satisfaction and the second measurement goal is that the provider and/or vendor is involved with the quality assurance provided by the vendor to the provider. 


\section{Quality Measurement of Telephony Service for Customer Satisfaction}

In relation to customer satisfaction, telephone service quality measurements are carried out in a sampling of phone customers of the providers, thus the measured is QoE (Quality of Experience) rather than QoS (Quality of Service). In this type of measurement, the measured parameter is the quality of the telephone conversation, which is the indicator of the transmitted end-to-end telephony service.

This type of Quality of Experience is shown in the form of Mean Opinion Score (MOS), and the size of the MOS value is between 1.0 and 4.5 depending on the quality of the sound during conversation. In detail, MOS = 1.0 corresponds to a customer statement that feels absolutely unable to hear the conversation; instead, MOS $=4.5$ is representing a very satisfied customer for the quality of the call.

Note: as a benchmark, there are some providers that provide MOS values in the range of 1 and 5 (not from 1 and 4.5).

The subjective measurement technique applies the statistical science and combines it with knowledge of ITU-T Recommendation P.830, 1996, which is a subjective method for quality assessment of broadband band and digital encoding aspects.

The application of statistical science should be accompanied by an in-depth understanding of the customer characteristics of the service provider, where the number of respondents interviewed is generally much more than the amount required for data processing.

For example, we only need data to be processed as many as 100 customers, then we should have 100 respondents who meet all the criteria of the type of customer provider, assume that is that meet the criteria for comparison of female and male customers, e.g. $55 \%$ versus $45 \%$, and also meet the customer age criteria, e.g. $60 \%$ of youth and $40 \%$ of established age, also meet the criteria of income level, e.g. $65 \%$ lower and $35 \%$ middle, and should meeting the criteria of call intensity, e.g. $75 \%$ rarely call and $25 \%$ more than three times a day. As an 
example of calculation, of all respondents who meet the criteria of the provider's customers, $20 \%$ stated that the quality of telephone conversations is very good, $50 \%$ said well, $15 \%$ said enough, and $10 \%$ said bad and 5\% said the absolutely unable to hear the conversation. Then $\operatorname{MOS}=20 \% * 4.5+50 \% * 3.5+15 \% * 2.5+10 \% * 1.5+5 \% * 1=3.225$ which state that the quality is relatively good.

\section{Quality Measurement of the Network and Telephony Services in Relation between Provider and Vendor}

Measurements of network performance and quality of telephone services in relation to vendors should be done based on the aggregate data, not a sampling, and should refer to the Signaling Ladder Diagram of the telephony services. The problem faced by the provider is almost the vendor's Signaling Ladder Diagram is not $100 \%$ the same as the Signaling Ladder Diagram compiled by International Standard ETSI and 3 GPP.

Some important parameters on this type of measurement are:

1) NER (Network Effectiveness Ratio)

2) Telephony Service Non-Accessibility

3) Telephony Setup Time $=$ PDD (Post Dial Delay)

4) Telephony Speech Quality (objective method), and

5) Telephony Cut-off Call Ratio = Drop Call Ratio.

\subsection{Signaling Ladder Diagram of Telephony Service on Cellular Network}

SLD of telephony service on $3 \mathrm{G}$ cellular network refer to ETSI standard is shown in table 3 .

Table 3. Signaling Ladder Diagram of 3G Network (ETSI Standard, not $100 \%$ fulfilled by the Vendors)

\begin{tabular}{|l|l|l|l|l|}
\hline Trigger Point & $\begin{array}{l}\text { Logical } \\
\text { Channel }\end{array}$ & Signal Name & $\begin{array}{l}\text { Outgoing } \\
\text { Network } \\
\text { Element }\end{array}$ & $\begin{array}{l}\text { Incoming } \\
\text { Network } \\
\text { Element }\end{array}$ \\
\hline $\begin{array}{l}\text { START of } \\
\text { NER and PDD } \\
\text { measurement: } \\
\begin{array}{l}\text { Push } \\
\text { The } \\
\text { button. }\end{array}\end{array}$ & RRC CONNECTION REQUEST & UE & RNC1 \\
\hline
\end{tabular}




\begin{tabular}{|c|c|c|c|}
\hline & RADIO LINK SETUP REQUEST & RNC1 & NODE B1 \\
\hline & RADIO LINK SETUP RESPONSE & NODE B1 & RNC1 \\
\hline & ESTABLISH REQUEST (AAL2) & $\mathrm{RNC1}$ & NODE B1 \\
\hline & ESTABLISH CONFIRM (AAL2) & NODE B1 & $\mathrm{RNC1}$ \\
\hline & DOWNLINK SYNCHRONISATION & RNC1 & NODE B1 \\
\hline & UPLINK SYNCHRONISATION & NODE B1 & RNC1 \\
\hline $\mathrm{CCCH}$ & RRC CONNECTION SETUP & RNC1 & UE1 \\
\hline & INSYNCH IND & UE1 & NODE B1 \\
\hline & RADIO LINK RESTORE INDICATION & NODE B1 & RNC1 \\
\hline $\mathrm{DCCH}$ & RRC CONNECTION SETUP COMPLETE & $\mathrm{RNC1}$ & UE1 \\
\hline $\mathrm{DCCH}$ & INITIAL DT (CM SERVICE REQUEST) & UE1 & RNC1 \\
\hline & $\begin{array}{l}\text { SCCP CONNECTION RQ [INITIAL } \\
\text { MESSAGE (CM SERVICE REQUEST)] }\end{array}$ & $\mathrm{RNC1}$ & MSC/VLR1 \\
\hline & SCCP CONNECTION CONFIRM & MSC/VLR1 & $\mathrm{RNC1}$ \\
\hline & COMMON ID & $\mathrm{RNC1}$ & MSC/VLR1 \\
\hline & LOCATION REPORTING CONTROL & MSC/VLR1 & $\mathrm{RNC1}$ \\
\hline & SECURITY MODE COMMAND & MSC/VLR1 & RNC1 \\
\hline $\mathrm{DCCH}$ & SECURITY MODE COMMAND & $\mathrm{RNC1}$ & UE1 \\
\hline $\mathrm{DCCH}$ & SECURITY MODE COMPLETE & UE1 & RNC1 \\
\hline & SECURITY MODE COMPLETE & $\mathrm{RNC1}$ & MSC/VLR1 \\
\hline & DT [IDENTITY REQUEST] (IMEI) & $\mathrm{RNC1}$ & MSC/VLR1 \\
\hline $\mathrm{DCCH}$ & DLDT [IDENTITY REQUEST] (IMEI) & RNC1 & UE1 \\
\hline $\mathrm{DCCH}$ & ULDT [IDENTITY RESPONSE] (IMEI) & UE1 & RNC1 \\
\hline & DT [IDENTITY RESPONSE] (IMEI) & RNC1 & MSC/VLR1 \\
\hline $\mathrm{DCCH}$ & ULDT [SETUP] & UE1 & $\mathrm{RNC1}$ \\
\hline & DT [SETUP] & $\mathrm{RNC1}$ & MSC/VLR1 \\
\hline & DT [CALL PROCESSING] & MSC/VLR1 & RNC1 \\
\hline $\mathrm{DCCH}$ & DLDT [CALL PROCEEDING] & RNC1 & UE1 \\
\hline & RAB ASSIGNMENT REQUETS & MSC/VLR1 & RNC1 \\
\hline & ESTABLISH REQUETS (AAL2) & $\mathrm{RNC1}$ & MGW \\
\hline & ESTABLISH CONFIRM (AAL2) & MGW & RNC1 \\
\hline & RADIO LINK RECONFIG PREPARE & $\mathrm{RNC1}$ & NODE B1 \\
\hline & RADIO LINK RECONFIG READY & NODE B1 & RNC1 \\
\hline & ESTABLISH REQUETS (AAL2) & $\mathrm{RNC1}$ & NODE B1 \\
\hline & ESTABLISH CONFIRM (AAL2) & NODE B1 & RNC1 \\
\hline & RADIO LINK RECONFIG COMMIT & $\mathrm{RNC1}$ & NODE B1 \\
\hline $\mathrm{DCCH}$ & RADIO BEARER SETUP & $\mathrm{RNC1}$ & UE1 \\
\hline & RAB ASSIGNMENT RESPONSE & RNC1 & MSC/VLR1 \\
\hline $\mathrm{DCCH}$ & RADIO BEARER SETUP COMPLETE & UE1 & RNC1 \\
\hline & IAM & MSC/VLR1 & MSC/VLR2 \\
\hline & PAGING & MSC/VLR2 & RNC2 \\
\hline $\mathrm{PCH}$ & PAGING TYPE 1 & $\mathrm{RNC2}$ & UE2 \\
\hline $\mathrm{CCCH}$ & RRC CONNECTION REQUEST & UE2 & $\mathrm{RNC2}$ \\
\hline & RADIO LINK SETUP REQUEST & RNC2 & NODE B2 \\
\hline & RADIO LINK SETUP RESPONSE & NODE B2 & $\mathrm{RNC2}$ \\
\hline
\end{tabular}




\begin{tabular}{|c|c|c|c|}
\hline & ESTABLISH REQUEST (AAL2) & RNC2 & NODE B2 \\
\hline & ESTABLISH CONFIRM (AAL2) & NODE B2 & $\mathrm{RNC2}$ \\
\hline & DOWNLINK SYNCHRONISATION & RNC2 & NODE B2 \\
\hline & UPLINK SYNCHRONISATION & NODE B2 & $\mathrm{RNC2}$ \\
\hline $\mathrm{CCCH}$ & RRC CONNECTION SETUP & $\mathrm{RNC2}$ & UE2 \\
\hline & INSYNCH IND & UE2 & NODE B2 \\
\hline & RADIO LINK RESTORE INDICATION & NODE B2 & $\mathrm{RNC2}$ \\
\hline DCCH & RRC CONNECTION SETUP COMPLETE & UE2 & $\mathrm{RNC2}$ \\
\hline $\mathrm{DCCH}$ & $\begin{array}{l}\text { PAGING RESPONSE / DDCH: INITIAL } \\
\text { DT }\end{array}$ & UE2 & $\mathrm{RNC} 2$ \\
\hline & SCCP CONNECTION REQUEST & $\mathrm{RNC2}$ & MSC/VLR2 \\
\hline & $\begin{array}{l}\text { UE CONNECTION ESTABLISH (PAGING } \\
\text { RESPONSE) }\end{array}$ & $\mathrm{RNC2}$ & MSC/VLR2 \\
\hline & SCCP CONNECTION CONFIRM & MSC/VLR2 & $\mathrm{RNC2}$ \\
\hline & COMMON ID & RNC2 & MSC/VLR2 \\
\hline & LOCATION REPORTING CONTROL & MSC/VLR2 & RNC2 \\
\hline & SECURITY MODE COMMAND & MSC/VLR2 & $\mathrm{RNC2}$ \\
\hline DCCH & SECURITY MODE COMMAND & $\mathrm{RNC} 2$ & UE2 \\
\hline DCCH & SECURITY MODE COMPLETE & $\mathrm{RNC2}$ & UE2 \\
\hline & SECURITY MODE COMPLETE & $\mathrm{RNC2}$ & MSC/VLR2 \\
\hline & DT [IDENTITY REQUEST] (MEI) & MSC/VLR2 & $\mathrm{RNC2}$ \\
\hline & [IDENTITY REQUEST](IMEI) & RNC2 & MSC/VLR2 \\
\hline DCCH & [IDENTITY RESPONSE] (IMEI) & $\mathrm{RNC2}$ & UE2 \\
\hline DCCH & DT [IDENTITY RESPONSE] (IMEI) & UE2 & $\mathrm{RNC2}$ \\
\hline & DT [IDENTITY RESPONSE] (IMEI) & MSC/VLR2 & $\mathrm{RNC} 2$ \\
\hline & DT [SETUP] & $\mathrm{RNC2}$ & MSC/VLR2 \\
\hline DCCH & DLDT [SETUP] & $\mathrm{RNC} 2$ & UE2 \\
\hline $\mathrm{DCCH}$ & DLDT [SETUP] & RNC2 & UE2 \\
\hline $\mathrm{DCCH}$ & ULDT [CALL CONFIRMED] & UE2 & $\mathrm{RNC2}$ \\
\hline & DT & MSC/VLR2 & $\mathrm{RNC2}$ \\
\hline & RAB ASSIGNMENT REQUETS & MSC/VLR2 & RNC2 \\
\hline & ESTABLISH REQUETS (AAL2) & $\mathrm{RNC2}$ & MGW \\
\hline & ESTABLISH CONFIRM (AAL2) & MGW & $\mathrm{RNC2}$ \\
\hline & RADIO LINK RECONFIG PREPARE & RNC2 & NODE B2 \\
\hline & RADIO LINK RECONFIG READY & NODE B2 & $\mathrm{RNC2}$ \\
\hline & ESTABLISH REQUETS (AAL2) & $\mathrm{RNC2}$ & NODE B2 \\
\hline & ESTABLISH CONFIRM (AAL2) & NODE B2 & $\mathrm{RNC} 2$ \\
\hline & RADIO LINK RECONFIG COMMIT & $\mathrm{RNC2}$ & NODE B2 \\
\hline $\mathrm{DCCH}$ & RADIO BEARER SETUP & RNC2 & UE2 \\
\hline & RAB ASSIGNMENT RESPONSE & RNC2 & MSC/VLR2 \\
\hline $\mathrm{DCCH}$ & RADIO BEARER SETUP COMPLETE & UE2 & RNC2 \\
\hline $\mathrm{DCCH}$ & ULDT [ALERTING] & UE2 & RNC2 \\
\hline & DT [ALERTING] & RNC2 & MSC/VLR2 \\
\hline & $\mathrm{ACM}$ & MSC/VLR2 & MSC/VLR1 \\
\hline & DT [ALERTING] & MSC/VLR1 & $\mathrm{RNC2}$ \\
\hline
\end{tabular}




\begin{tabular}{|c|c|c|c|c|}
\hline $\begin{array}{l}\text { STOP of NER } \\
\text { and PDD } \\
\text { measurement: } \\
\text { Alerting tone } \\
\text { is heard by } \\
\text { the A-party } \\
\text { coming from } \\
\text { the B-party } \\
\text { AND B-party } \\
\text { rings. }\end{array}$ & & DLDT [ALERTING] & RNC2 & UE1 \\
\hline \multirow[t]{4}{*}{$\begin{array}{l}\text { START of } \\
\text { Drop Call } \\
\text { Measurement: } \\
\text { The } \\
\text { CONNECT } \\
\text { message on the } \\
\text { DCCH } \\
\text { logical channel } \\
\text { is passed from } \\
\text { the MSC to the } \\
\text { UE to indicate } \\
\text { that the } \\
\text { connection has } \\
\text { been } \\
\text { established. }\end{array}$} & DCCH & DT [CONNECT] & MSC/VLR1 & RNC1 \\
\hline & & DLDT [CONNECT] & $\mathrm{RNC1}$ & UE1 \\
\hline & $\mathrm{DCCH}$ & ULDT [CONNECT ACK] & UE1 & $\mathrm{RNC1}$ \\
\hline & & DT [CONNECT ACK] & $\mathrm{RNC1}$ & MSC/VLR1 \\
\hline $\begin{array}{l}\text { STOP of Drop } \\
\text { Call } \\
\text { Measurement: } \\
\text { A } \\
\text { DISCONNECT } \\
\text { message on the } \\
\text { DCCH } \\
\text { logical channel } \\
\text { is sent from the } \\
\text { UE (message } \\
\text { sent when the } \\
\text { user ends the } \\
\text { call). }\end{array}$ & DCCH & ULDT [DISCONNECT] & UE1 & RNC1 \\
\hline
\end{tabular}

\subsection{NER (Network Effectiveness Ratio) Measurement}

Network Effectiveness Ratio is a measure of the quality of the network without applying the

A-party error and B-party busy.

Analysis: NER measurement data based on the counter in the MSC and or MGW which records all incoming signals, whether successfully processed or failed processing. The possibility of failure, other than those caused by a failure in the process of signal transmission and signal processing in network elements, is caused by the failure of these processes below: 
- Radio Link setup and establish by node B1 (node B of A-party)

- Downlink and uplink synchronization by node B1 and RNC1

- RRC connection setup by node B1 and UE1

- SCCP connection by MSC1 \& VLR1

- Location control by MSC1 \& VLR1 and RNC1

- Authentication process of UE1, If it fails, it is not taken into account in the NER

- The same process as above to UE2 (= B-party), node B-2, RNC2 and MSC \& VLR2

\subsection{Measurement of the Telephony Service Non- Accessibility}

The probability that the end user cannot access the Mobile Telephony Service when displaying of the network indicator on the mobile device is in good condition, which suggests that the availability and accessibility network is good. The terms of the QoS measurement should take into account that the B-party is not in the busy states, and no A-error states.

In cellular networks, the measurement begins when the A-party pressed the Send button. At that time the cellphone will send a signal "RRC CONNECTION REQUEST" to BTS or NodeB. Once the core network receives this signal, then do the preparation of the $\mathrm{CCCH}$ logical channel mapped to the RACH transport channel. It is possible that there is more than one RRC CONNECTION REQUEST per attempt, in this case only one signal that counts. It is possible that the RRC connection established because of the Location Update is wrong; in this case, test sample should be removed.

Successful call attempt is marked by the presence of Alerting tone is heard by the A-party, AND B-party rings.

Abstract Equation of Telephony Service Non-Accessibility:

$$
\text { TelephonyService Non - Accessibility }(\%)=\frac{\text { unsuccessfull call attempts }}{\text { all call attempts }} x 100
$$




\subsection{Measurement of the Telephony Setup Time = PDD (Post Dial Delay)}

Telephony Setup Time describes the duration of customer presses the send button (= mobile station sending the complete address information to the network) and customer receive the call set-up notification (receive the connect established message).

Abstract Equation of Telephony Setup Time:

$$
\text { TelephonySetup Time }=t_{\text {connect_establishel }}-t_{\text {sendingof complete addressin }}
$$

Analysis: Measurement of telephony setup time is done based on the data at the timer in the MSC / MGW which records the time of arrival signal and the release signals. In general, if all signaling goes normal, the processing time of the entire signal, plus the propagation time is only a few hundred milliseconds. But, the telephony setup time may be measured in a few seconds, this is happening cause of the processing time of tens of signals. The waiting time will be greater if the resource-pool is available in limited quantities. Telephony setup time does not take into account the elapsed time by a signaling failure. Signaling that fail will only affect the performance of the NER and other performance-measured in the counter.

\subsection{Measurement the Telephony Speech Quality}

Based on the recommendations of the ITU-T, there are two ways to measure the value of MOS objectively, including:

a) Refer to ITU-T P.862 (ITU-T Recommendation P.862, 2001), which use the concept of Perceptual Evaluation of Speech Quality (PESQ) is an objective method for assessing the quality of the conversation end-to-end narrow-band telephone networks and speech codecs

b) Refer to the Recommendation ITU-T G.107 (E-model) (ITU-T Recommendation G.107, 2014), which is a calculation of predictable sound quality as perceived by customers for telephone connection end-to-end using passive methods. 


\subsubsection{ITU-T Recommendation G.107 (E-model).}

The calculation of the predicted sound quality as perceived by customers for telephone connection end-to-end using passive methods can be done using a transmission planning Emodel. E-model takes into account various telephony disorders, particularly due to interference from the low bit rate coding devices, one-way delay, and disruption of classic telephony is loss, noise, and echo. E-model can be used to calculate the R factor, known as the transmission rating factor, which is a simple measure of the quality of the sound. The $\mathrm{R}$ factor can be transformed into a quality index as Mean Opinion Score (MOS), Percentage Good or Better (Gob), or Percentage Poor or Worse (POW).

\subsubsection{Telephony voice quality calculation procedure (using the $\mathbf{R}$ factor)}

1. Calculate the $\mathrm{R}$ factor use the formula

$$
\mathrm{R}=\mathrm{Ro}-\mathrm{Is}-\mathrm{Id}-\mathrm{Ie}-\mathrm{eff}+\mathrm{A}
$$

Where:

- Ro represents the SNR (signal-to-noise-ratio), including noise sources such as noise circuit and room noise.

- Is a combination of all the distractions that occur simultaneously with the voice signal?

- Id Factor is a disorder caused by the delay.

- Ie-eff (effective equipment impairment factor) represents the interference caused by the low bitrate codec, and the disruption caused by loss of packet at random.

- The A factor is an advantage that allows the compensation of the factors that caused the disruption another advantage of the user access.

2. After obtaining the $\mathrm{R}$ factor, then calculate the factor $\mathrm{E}$, use the formula:

$$
\mathrm{E}=\frac{1}{\sqrt{2 \pi}} \int_{-\infty}^{x} e^{\frac{t^{2}}{2}} d t[18]
$$

3. After obtaining the E factor, then the sound quality telephony is calculated use the formula:

- Percentage Good or Better (Gob) is calculated using the formula:

$$
\mathrm{G} o B(\%)=\frac{\mathrm{R}-60}{16} * 100 \quad[18]
$$

- Percentage Poor or Worse (POW) is calculated using the formula 


$$
\operatorname{PoW}(\%)=\frac{45-\mathrm{R}}{16} * 100[18]
$$

- MOSCQE (MOS Conversational Quality Estimate) is calculated using the formula

- for $\mathrm{R}<0$, then: $\mathrm{MOSCQE}=1$

- for $0<\mathrm{R}<100$, then: MOSCQE $=1+0.035 \mathrm{R}+0.000001 \mathrm{R} *(\mathrm{R}-60) *(100-$ $\mathrm{R}) * 7$

- $\quad$ for $\mathrm{R}>100$, then: MOSCQE $=4.5$

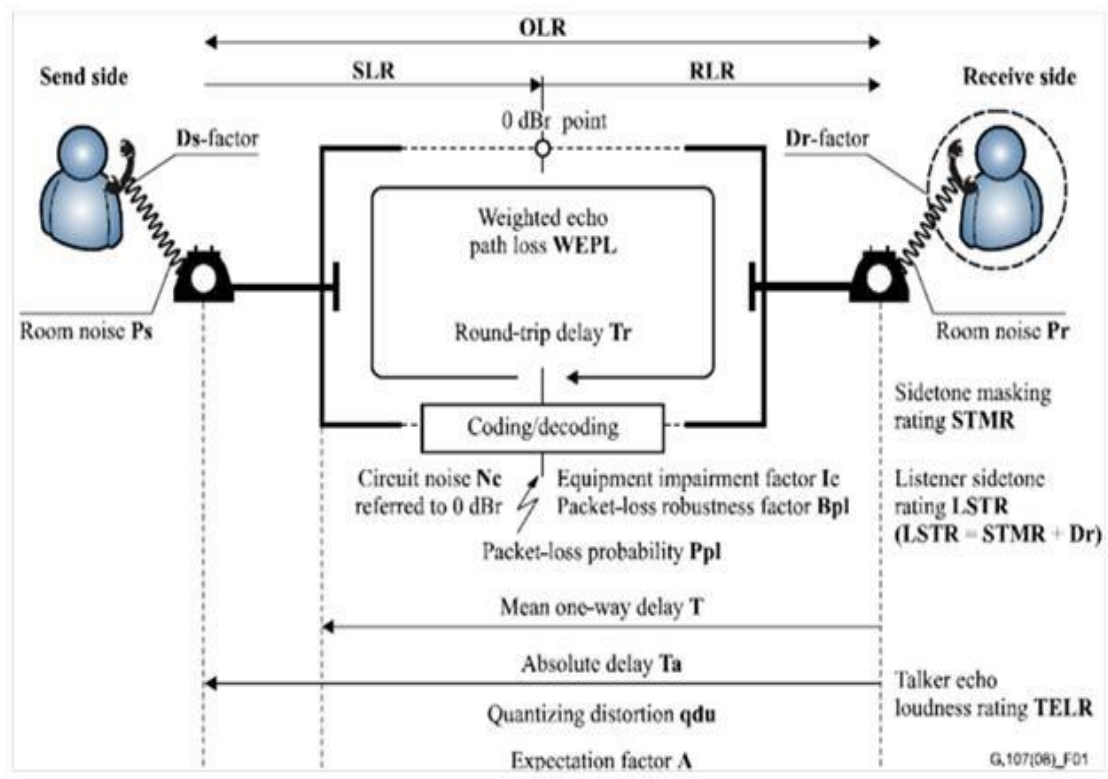

Figure 1. E Models (ITU-T Rec. G107)

Where:

- SLR (Send Loudness Rating)

- RLR (Receive Loudness Rating)

- OLR (Overall Loudness Rating)

- STMR (Side tone Masking Rating)

- LSTR (Listener Side tone Rating)

- Ds (D-value of telephone at send-side)

- Dr (D-value of telephone at receive-side)

- TELR (Talker Echo Loudness Rating)

- WEPL (Weighted Echo Path Loss)

- T (Mean one way delay of the echo path)

- $\operatorname{Tr}$ (Round-trip delay in a closed 4-wire loop)

- Ta (Absolute one-way delay in echo free connections)

- qdu (Number of quantization distortion units)

- Ie (Equipment impairment factor)

- Ppl (Random packet-loss probability)

- Bpl (Packet-loss robustness factor)

- $\mathrm{Nc}$ (Circuit noise referred to the $0 \mathrm{dBr}$-point) 
- Nfor (Noise floor at the receive-side)

- Ps (Room noise at the send-side)

- Pr (Room noise at the receive-side)

- A (Advantage factor)

Table 1. Default Parameters value

\begin{tabular}{|l|c|c|c|c|}
\hline \multicolumn{1}{|c|}{ Parameter } & Abbr. & Unit & $\begin{array}{c}\text { Default } \\
\text { value }\end{array}$ & $\begin{array}{c}\text { Permitted } \\
\text { range }\end{array}$ \\
\hline Send loudness rating & SLR & dB & +8 & $0 \ldots+18$ \\
\hline Receive loudness rating & RLR & dB & +2 & $-5 \ldots+14$ \\
\hline Sidetone masking rating & STMR & dB & 15 & $10 \ldots 20$ \\
\hline Listener sidetone rating & LSTR & $\mathrm{dB}$ & 18 & $13 \ldots 23$ \\
\hline D-Value of telephone, send side & Ds & - & 3 & $-3 \ldots+3$ \\
\hline D-Value of telephone, receive side & Dr & - & 3 & $-3 \ldots+3$ \\
\hline Talker echo loudness rating & TELR & $\mathrm{dB}$ & 65 & $5 \ldots 65$ \\
\hline Weighted echo path loss & WEPL & $\mathrm{dB}$ & 110 & $5 \ldots 110$ \\
\hline Mean one-way delay of the echo path & $\mathrm{T}$ & $\mathrm{ms}$ & 0 & $0 \ldots 500$ \\
\hline Round-trip delay in a 4-wire loop & $\mathrm{Tr}$ & $\mathrm{ms}$ & 0 & $0 \ldots 1000$ \\
\hline Absolute delay in echo-free connections & $\mathrm{Ta}$ & $\mathrm{ms}$ & 0 & $0 \ldots 500$ \\
\hline Number of quantization distortion units & $\mathrm{qdu}$ & - & 1 & $1 \ldots 14$ \\
\hline Equipment impairment factor & $\mathrm{Ie}$ & - & 0 & $0 \ldots 40$ \\
\hline Packet-loss robustness factor & $\mathrm{Bpl}$ & - & 4.3 & $4.3 \ldots 40$ \\
\hline Random packet-loss probability & $\mathrm{Ppl}$ & $\%$ & 0 & $0 \ldots 20$ \\
\hline Burst ratio & $\mathrm{BurstR}$ & - & 1 & $1 \ldots 8$ \\
\hline Circuit noise referred to 0 dBr-point & $\mathrm{Nc}$ & $\mathrm{dBm} 0 \mathrm{p}$ & -70 & $-80 \ldots-40$ \\
\hline Noise floor at the receive side & $\mathrm{Nfor}$ & $\mathrm{dBmp}$ & -64 & - \\
\hline Room noise at the send side & $\mathrm{Ps}$ & $\mathrm{dB}(\mathrm{A})$ & 35 & $35 \ldots 85$ \\
\hline
\end{tabular}

Table 2. The Correlation between Satisfactions with 4 Parameters

\begin{tabular}{|c|c|c|c|l|}
\hline $\begin{array}{c}R \text {-value } \\
\text { (lower } \\
\text { limit) }\end{array}$ & $\begin{array}{c}\text { MOSCQE } \\
\text { (lower } \\
\text { limit) }\end{array}$ & $\begin{array}{c}\text { GoB (\%) } \\
\text { (lower } \\
\text { limit) }\end{array}$ & $\begin{array}{c}\text { Pow (\%) } \\
\text { (upper } \\
\text { limit) }\end{array}$ & $\begin{array}{c}\text { User } \\
\text { satisfaction }\end{array}$ \\
\hline 90 & 4.34 & 97 & $\sim 0$ & Very satisfied \\
\hline 80 & 4.03 & 89 & $\sim 0$ & Satisfied \\
\hline 70 & 3.60 & 73 & 6 & Some users dissatisfied \\
\hline 60 & 3.10 & 50 & 17 & Many users dissatisfied \\
\hline 50 & 2.58 & 27 & 38 & Nearly all users dissatisfied \\
\hline
\end{tabular}

\subsection{Measurement the Telephony Cut-off Call Ratio (= Drop Call Ratio)}

Telephony Cut-off Call Ratio calculation of the probability of a successful call is not terminated by the normal termination.

The normal termination of telephone connections only occur when:

1) The A-party hang-up the connection, and/or

2) The A-party still holds on, but the B-party hang-ups, then the normal termination occur in 30 seconds after the B-party hangs up.

Telephony cut-off call occurs when termination occurs abnormally. 
The measurement of the Telephony Cut-off Call Ratio begins when alerting or busy tone heard by the A-party coming from B-party. In cellular networks, START: The CONNECT message on the DCCH logical channel is passed from the MSC to the MS to indicate that the connection has been established. NORMALLY, STOP: Release of connection directly by A- or B-party, marked by A DISCONNECT message on the DCCH logical channel is sent from the UE (message sent when the user ends the call).

Abstract Equation of Telephony Cut-off Call Ratio:

$$
\text { Telephonycut }- \text { off call ratio }=\frac{\text { unintentionally terminated telephonycalls }}{\text { all successful telefphon y call attempts }}
$$

Practical experience shows that the event of the cut-off of the phone call is in progress when the SLD shows this reason.

\section{Measurement of the Network and Telephone Service on 4G and 5G Cellular Networks}

The $4 \mathrm{G}$ and $5 \mathrm{G}$ cellular networks have characteristics very different from their predecessors, where there are two very principal differences:

a) The 4G and 5G mobile networks are fully IP-based or end to end IP, as a result, SLD from the network is simpler than that of $3 \mathrm{G}$ networks because $4 \mathrm{G}$ and $5 \mathrm{G}$ networks no longer have network-elements that separate the circuit-switched and packet switched as found on $3 \mathrm{G}$ networks.

b) Telco should develop the IP-based telephone service, otherwise if it does not work, then the over-the-top (OTT) provider's telephone service will dominate, so the network performance measurement will be done separately with service quality measurement, where the network performance is the responsibility of Telco, on the other hands, the service quality depends on the quality of the OTT provider.

\section{References}

[1] Haryadi, S. (2018, February 26). Measurement of Cellular Network's Availability and Reliability based on the Signaling Ladder Diagram. Retrieved from osf.io/preprints/inarxiv/hwvm8

[2] European Telecommunications Standards Institute. (2011). Speech and multimedia Transmission Quality (STQ), QoS aspects for popular services in mobile networks; Part 1. Assessment of Quality of Service, ETSI TS 102 250-1 V2.2.1

[3] European Telecommunications Standards Institute. (2011). ETSI Standard TS 102 250-2 v2.2.1: Speech and multimedia Transmission Quality (STQ); QoS aspects for popular services in mobile networks; Part 2: Definition of Quality of Service parameters and their computation.

[4] ETSI. (2008). ETSI Standard EG 202-057 V1.3.1: Speech Processing, Transmission and Quality Aspects (STQ). 
[5] ITU-T. (2014). ITU-T Recommendation G.107: The E-Model, a computational model for use in transmission planning.

[6] Sigit Haryadi. (2013). Telecommunication Traffic: Technical and Business Consideration. Lantip Safari Media, Bandung, Indonesia. ISBN: 978-602-18578-5-4.

[7] Sigit Haryadi. (2013). Telecommunication Service and Experience Quality. Lantip Safari Media, Bandung, Indonesia. ISBN: 978-602-18578-6-1.

[8] Haryadi, Sigit; Limampauw, Ivantius. (2012). QoS Measurement of Telephony Services In 3G Networks Using Aggregation Method. Conference Proceeding of TSSA 2012. Denpasar, Indonesia.

[9] Haryadi, Sigit; Nusantara, Sandy. (2012). QoS Measurement of Web Browsing Services In 3G Networks Using Aggregation Method. Conference Proceeding of TSSA 2012. Denpasar, Indonesia.

[10] Haryadi, Sigit; Pramudita, Arnold. (2012). QoS Measurement of Video Streaming Services in a 3G Networks Using Aggregation Method. Conference Proceeding of TSSA 2012. Denpasar, Indonesia.

[11] Haryadi, Sigit; Andina, Raisha. (2012). QoS Measurement of File Transfer Protocol Services In 3G Networks Using Aggregation Method. Denpasar, Indonesia. 2012.

[12] Haryadi, S. (2018, January 25). Chapter 1. The Concept of Telecommunication Network Performance and Quality of Service. Retrieved from osf.io/mukqb

[13] Haryadi, S. (2018, January 26). Chapter 2 of Network Performance and Quality of Service: Determination of Key Performance Indicator (KPI). Retrieved from osf.io/preprints/inarxiv/6gtnd

[14] Haryadi, S. (2018, January 26). Chapter 3 of Network Performance and Quality of Service: Technical Measurement of a Mobile Network Performance and Quality of Service. Retrieved from osf.io/q4wsz

[15] Haryadi, S. (2018, January 30). Basic Calculation of the Network's Availability and Reliability (Chapter 4 of Network Performance and Quality of Service). Retrieved from osf.io/preprints/inarxiv/z5mwq

[16] Muhammad Rizky Hikmatullah; Sigit Haryadi. (2017). Perceptual evaluation of speech quality over the top call service. 3rd International Conference on Wireless and Telematics (ICWT), Indonesia.

[17] Rizna Nofitasari; Sigit Haryadi. (2017). Self-healing mechanism with RSRP measurement in LTE network. 3rd International Conference on Wireless and Telematics (ICWT), Indonesia.

[18] Fidyatun Nisa; Sigit Haryadi. (2016). Simulation of the fault management with Self Healing mechanism (case study: LTE Network in Banda Aceh Area). 10th International Conference on Telecommunication Systems Services and Applications (TSSA), Indonesia.

[19] Suci Ramadona; Sigit Haryadi; Dyah Rakhma Aryanti. (2015). Over the top call service key performance indicator. 1st International Conference on Wireless and Telematics (ICWT), Indonesia.

[20] Maya Rahayu; Sigit Haryadi; Dyah Rakhma Aryanti. (2015). Over the Top chat service key performance indicator. 1st International Conference on Wireless and Telematics (ICWT), Indonesia.

[21] Sigit Haryadi. (2016). Telecommunication Quality of Service Concept. Research gate. Available online at https://www.researchgate.net/publication/313101013_Telecommunication_Quality_of Service_Concept 
[22] Sigit Haryadi. (2016). Grade of Service \& Quality of Service Concept and Analysis. Researchgate. Available online at https://www.researchgate.net/publication/313101070_Grade_of_Service_Quality_of_ Service_Concept_and_Analysis

[23] Sigit Haryadi. (2016). Performance Indicator of Telecommunication Service. Researchgate. Available online at https://www.researchgate.net/publication/313101244_Performance_Indicator_of_Tele communication_Service. 